\title{
La inspiración bíblica y sus dimensiones sociales
}

El tema de la inspiración bíblica, a pesar de los esfuerzos seculares de un sinnúmero de teólogos y escriturarios, sigue conservanido perenne actualidad, acaso porque van emparejados en torno a él el interés y las dificultades, como ocurre con todos los problemas enraizados en el misterio.

En la Biblia sólo hallamos dos referencias ${ }^{1}$ que sirvieron de apoyo a los antiguos y modernos que abordaron esta materia. Desde la época patrística, sin alardes de tecnicismos, pero de forma clara y concreta, con expresiones rebosantes de naturalidad y candor, se consideró a los hagiógrafos como instrumentos de Dios y se acentuó con rara uniformidad que Dios es el autor de los libros santos.

Los teólogos medievales centraron su atención en el estudio de los problemas que giran en torno a la profecía.

A partir del siglo xvı, como reacción ante la postura protestante y con marcada tendencia apologética, tomando como punto de partida la doctrina tomista sobre la profecía, se define a ultranza la inspiración de la Biblia, testimonio de la revelación divina, junto con la tradición.

Desde el siglo xIx, ante los portentosos avances de la crítica histórica y literaria, de las ciencias físicas y naturales, etc., se plantea inevitablemente el problema de las relaciones entre la inspiración y la inerrancia. Se ahonda en las profundidades de los misteriós de la inspiración por dos caminos convergentes: la teoría de la instrumentalidad y el concepto de autor.

Después del Concilio Vaticano I se centran los esfuerzos de los tcólogos y biblistas en conocer lo que ha dado en llamarse la psicología de la inspiración. Los investigadores católicos hallaron directrices y sugerencias alentadoras en las Encíclicas pontificias tales como la "Providentissi-

12 Tim. 3, 16; 2 Pe. 1, 20-21. 
mus" de León XIII, la "Spiritus Paraclitus" de Benedicto XV, la "Divino afflante Spiritu" de Pío XII y otras.

Ultimamente y con diversa fortuna, han surgido intentos y ensayos encaminados a descubrir un interesante y nuevo aspecto que suele denominarse, con terminología muy de nuestro tiempo, carácter social de la inspiración. Es cabalmente sobre lo que pretendemos informar. En conjunto, los esfuerzos han sido meritorios y los frutos copiosos y su estudio está reclamando una referencia incluso en los Manuales de Intraducción General. Al terminar de redactar estas notas ha llegado a nuestras manos la Introducción General a la Sagrada Escritura, redactada por un equipo de biblistas españoles, Madrid 1966, y constatamos con gozo que en las páginas 65-66 se dedica un apartado a la Sociología de la inspiración.

Anticipamos, como preámbulo, unas cuestiones introductorias y compendiosas que predisponen a la recta inteligencia del tema que nos ocupa.

Escritura y Palabra de Dios.

Que la Sagrada Escritura sea la Palabra de Dios es una especie de axioma refrendado por toda la tradición patrística y eclesiástica que se deriva directamente de la misma Sagrada Escritura ${ }^{2}$. Su proyección ha hallado eco en la Liturgia: el sacerdote o lector proclama con énfasis al terminar las lecturas bíblicas de la Misa: ¡Palabra de Dios! El misterio de la salvación por Cristo, que en el Antiguo Testamento es preparación y promesa y en el Nuevo cumplimiento y realidad, nos ha llegado parcialmente en forma de libros, pero que no son efecto de la actividad literaria física y personal de Dios, sino que Este, lo mismo que locutus est per prophetas, escribió por medio de los hagiógrafos. De ahí que los mensajes divinos nos lleguen por conducto de los hombres. No cabe desdeñar, ni desconocer la colaboración humana en la descripción y transmisión de los divinos misterios.

Por otra parte y de manera bien concreta y terminante, los libros escritos mediante esta especie de colaboración ideollógica y literaria (si se permite la expresión), tienen un destino evidente que no puede restringir-

2 Mc. 7, 13; Jo. 10, 35; Rom. 3, 2. 
se a los primeros lectores, sino que lleva en sí mismo dimensiones intencionales de universalidard.

Habida cuenta de estas elementales ideas, conviene adelantar que es preciso esclarecer y distinguir conceptos y aspectos de las mismas. No se puede hacer una equivalencia absoluta y total entre Escritura y Palabra de Dios, como si llegaran a identificarse, o como si fueran dos puras denominaciones de una misma cosa. En efecto, toda la Escritura es Palabra de Dios, pero es posible que no toda la Palabra de Dios (la revelación) esté expresada exclusivamente en los libros santos, sino que tenga otros canales igualmente transmisores de la divina Palabra. Al enunciar tal posibilidad, parece lógico que pensemos no sólo en ambos Testamentos, monumentos perennes y escritos de la divina Palabra, sino también en la transmisión de la misma por otros medios, como la tradición e incluso la Iglesia, receptora, conservadora y transmisora de la Palabra de Dios y como intermediaria con su pueblo. Así nos ponemos en condiciones de aclarar ideas y dar un paso adelante, sin peligro de confundir o simplificar con exceso las expresiones. Al mismo tiempo se dilata nuestro campo de observación, ya que la Palabra de Dios no es tan sólo el conjunto de libros bíblicos de los dos Testamentos, sino que, en otros términos, el influjo carismático de Dios en los hägiógrafos sagrados -inspiración escrituraria- ha podlido afectar también de forma similar a la tradición, sobre todo apostólica, y a la Iglesia. Así se rompería el círculo clásico adoptado en todos los Manuales de Introducción a la Sagrada Escritura que señalaba para la Palabra escrita un proceso cifrado en tres conceptos: Inspiración activa (en Dios), inspiración pasiva o recéptiva (en el hombre) e inspiración terminativa (en el libro). El afán de los teóllogos y bíblicos de nuestro tiempo pretende que el contenido de la inspiración escrituraria sea más amplio, hasta llegar al pueblo de Dios que es al que va destinada la Biblia.

Revelación y Palabra de Dios.

Es elemental proclamar nuestra incapacidad natural para conocer algo de la vida y de las obras divinas, fuera de lo que Dios mismo ha reflejado en sus criaturas ${ }^{3}$. Como dicen los teólogos, no podemos tras-

3 Y. M. J. Congar, La foi et la théologie, Turnai 1962, 9-12; F. M. GENUYT, Le Mystere de Dien, Tournai 1963 , 
pasar el orden natural e introducirnos en el sobrenatural, que está fuera de nuestro alcance. En las criaturas aparece algo de la eternidad y del poder de Dios (Rom. 1, 20), como también en nuestro interior es dable descubrir una ley natural (Rom. 2, 15). Las posibillidades de nuestro conocimiento de la divinidad a través de los reflejos divinos en las criaturas y en la conciencia, resultaron insuficientes, según lo atestigua la historia y la experiencia. El mismo San Pablo se lamentaba (Rom. 1, 21-23) de que los hombres hubieran desfigurado la idea de Dios ${ }^{4}$. No debemos olvidar las perniciosas consecuencias del pecado en las facultades específicas del hombre.

Quiso Dios remediar tales deficiencias y peligros mediante la revelación ${ }^{5}$ que actúa, por un lado comunicando a los hombres la intimidad de la vida divina que a la vez, por obra de la gracia, influye en las facultades del hombre, normalizando su conocimiento para que, libre de las taras del pecado, pueda, mediante su acción elevadora, penetrar en el misterio de Dios cuya imagen oscurecida brilla en las criaturas e incluso en sí mismo. La revelación, por otra parte, se canaliza por medio del lenguaje, de la Palabra. No exclusivamente por ella, puesto que también se sirve Dios de los acontecimientos, pero la palabra y la historia sagrada entran de lleno en los planes de Dios y entroncan directamente en el misterio de la salvación. Es decir, que Dios se deja ver en la historia y revela sus mensajes a los hombres.

la Palabra de Dios como medio de revelación.

Este es el aspecto que más directamente nos interesa y sobre el que insisten los comentaristas contemporáneos. Sin desdeñar, por supuesto, el valor de los acontecimientos históricos que, aunque a veces hayan sido restringidos o desfigurados por medios de expresión que adolecen de influencias filosóficas, siguen teniendo valor y están cargados de sentido, supuesto el conocimiento de la fe ${ }^{6}$.

Pero Dios se ha puesto también y, sobre todo, en comunicación con los hombres, mediante el lenguaje o las palabras de los mismos hom-

4 H. de LUBAC, Recherche de l'Homme nouveau, París 1949.

R. LatoureLLe, Théologie de la révélation, Brugesi 1963.

R. LATOURELLE, "Révélation, histoire et incarnation": Gregorianum 44 (1963) 225-262, 
bres $^{7}$. No por medio de un lenguaje suyo que hubiera resultado ininteligible, sino nuestro, es decir, humano. En esto consiste el misterio de Dios que, en un alarde suyo de condescendencia, va a servirse de las palabras humanas para expresar realidades divinas. Utiliza Dios una vez más las causas segundas como intermedias entre sí mismo y la humanidad. Habrá hombres que, por designio de Dios, sean portadores de palabras, valga la expresión, transmitiendo los mensajes divinos y aportando armónicamente a la revelación su colaboración personal, lo que dignifica y embellece al mismo tiempo las personas intermedias y el lenguaje.

Es lógico e inevitable que las expresiones humanas y concretas resulten insuficientes y a veces oscuras, porque son de su naturaleza limitadas e incapaces para expresar con exactitud las realidades divinas, pero eso mismo abre maravillosas perspectivas a los hombres que han de aplicar sus energías intelectuales, vigorizadas por la fe, en el transcurso de los siglos, a desvelar, en cuanto sea posible, los misterios divinos, salvando la corteza de las palabras, hasta dar con el contenido sobrenatural de las mismas. Como quiera que su riqueza de contenido es inagotable, nunca será infructuoso el esfuerzo humano, como está ampliamente comprobado por los progresos de las ciencias teológicas y bíblicas que día a día descubren tesoros nuevos enraizados en el misterio de la salvación. De este modo, es decir, por la palabra, las cosas divinas entran en el campo de nuestro conocimiento intelectual.

Otro aspecto interesante de la economía divina. La revelación se hace como por grados o etapas sucesivas, no de modo total o simultáneo. En el Antiguo Testamento nos llega la Palabra de Dios por medio de los profetas, intermediarios entre Dios y los hombres, mientras que en el Nuevo toma nuestra naturaleza el Verbo que personalmente pregona el misterio de nuestra salvación y encomienda a sus Apóstoles la difusión del Evangelio. Así, con un método pedagógico a lo divino, va llegando la Palabra de Dios con progresivo fulgor a las inteligencias de los hombres. Pero siempre resuena, a través de los intermediarios, la Palabra increada de Dios ${ }^{8}$.

7 J. DUPoNT, "Écriture et Tradition": Nouvelle revue théologiqque 85 (1963) 459 s.

L. Charlier, Lie Christ, Parole de Dieu cit. por P. Greilot, La Biblie, Parrole de Dieu, Tournai 1965; L. M. DewaIluY, Jésus-Christ, Parrole de Dien, París 1945. 
Palabra de Dios y pueblo de Dios.

Puesto que vamos en busca del carácter social de la inspiración, es menester que anticipemos unas ideas que nos ayuden a desentrañar no sólo el concepto abstracto de la Palabra de Dios, sino también el modo concreto como se ha manifestado a los hombres. A todos los hombres que son, en su proyección universal, el punto de mira por parte de Dios. Pero, con el testimonio fehaciente de la historia, el mensaje divino de su Palabra ha tenido y sigue teniendo una realización providencial que confirma, sin lugar a idudas, la parte fundamental que corresponde a los hombres en la historia de la revelación.

Primero eligió Dios un pueblo, Israel, a quien constituyó depositario en exclusiva de la Pallabra divina para que, supuesta su fe, pudiera tener acceso a un mayor conocimiento de Dios. Este pueblo tiene su historia, sus vicisitudes, su cultura, su lengua, etc. La Palabra de Dios preside y vivifica todo el ámbito del Antiguo Testamento en el que Dios habla a su pueblo, bien sea con sus obras, o por el ministerio de los profetas. En el Nuevo Testamento se ensanchan los límites de su pueblo, rompiendo los diques de todo nacionalismo, con el mensaje personal del Verbo encarnado y la cooperación subsecuente de los Apóstoles. No se puede desconocer, ni negar el influjo esencial de la Palabra de Dios en la constitución y en la vida tanto de la comunidad restringida del pueblo hebreo, como en la comunidad expansiva de la Iglesia.

Es, por tanto, indiscutible que la palabra de Dios va encaminada a ios hombres, al pueblo de Dios, lo que exige que se le proponga de manera que el lenguaje divino revista formas humanas que le hagan inteligible por parte de la comunidad a la que va destinado, es decir, que el pensamiento divino ha de revestirse de formas habituales y concordes con el lenguaje y la cultura del pueblo al que Dios habila. Para calar, por consiguiente, en el significado de la divina revelación, no se puede olvidar que esta va dirigida a su pueblo, mediante un lenguaje humano concreto que tiene sus particularidades ideológicas y expresivas que han de ser tenidas en cuenta, so pena de renunciar a una inteligencia cabal de los textos. Ya lo tienen muy en cuenta los exegetas de nuestros días. 
Transmisión de la Palabra divina.

En principio, según la experiencia suministrada por la historia de las Religiones, dos modos de transmisión parecen posibles: la tradición y la escritura ${ }^{9}$. En ciertos pueblos antiguos que carecieron de fuentes escritas, fue exclusivamente la tradición la que dio cauce a las ideas religiosas, apoyándose en diversos modos de comunicación, como predicación, ritos, etc. En otros pueblos, en cambio, se concretó el pensamiento religioso en libros que constituyeron el núcleo central en torno al que giraron las creencias y la vida religiosa. Entre ambos módulos extremos cabe hallar no pocas fórmulas intermedias. Con frecuencia la tradición primitiva cuaja más tarde en libros que, como es lógico, deben recoger y fijar las tradiciones con fidelidad, si aspiran a ser norma de la vida religiosa de las comunidades.

Dado tal planteamiento de posibilidades y habida cuenta del caso concreto de Israel que recogió en sus escritos no escaso caudal ideológico que derivaba de viejas tradiciones, es inevitable el que haya relaciones e interferencias entre ambas. Las dos, por otra parte, miran derechamente al pueblo de Dios. Por supuesto que dichas relaciones no fueron idénticas en los diversos tiempos históricos, es decir, en el Antiguo y en el Nuevo Testamento.

No entra en nuestro propósito analizar y discutir los diversos problemas que suscitan las ideas que vamos exponiendo y que, por otra parte, han sido formulados y expuestos por no pocos tratadistas de nuestro tiempo. Por ejemplo G. Grelot ${ }^{10}$ nos ofrece una síntesis orgánica y razonada del paso de la tradición a la Escritura en el pueblo hebreo, de las mutuas dependencias entre ambas, del hecho de la aparición de Cristo, Palabra de Dios en persona, en quien se cumple la revelación precedente, de forma que la.Ley, los profetas, etc., constituyen como una preparación pedagógica para entender el misterio de Cristo.

En torno a Cristo nace y se desarrolla una tradición y también unos escritos. Jesucristo no escribió nada y la literatura religiosa inspirada en sus obras y en sus palabras, en definitiva en su doctrina, sobre todo en torno a su resurrección, está respaldada autorizadamente sobre todo por

9 J. LeIPOLDT - S. MoRENZ, Heilige Sehriften, Leipzig 1953.

10 P. Grelot, La Bible, Parole de Dieu, Tournai 1965. 
los Apóstoles que forman el núcleo, no sólo de la literatura evangélica, sino también de una tradición que completa el angosto contenido de los evangelios. Esta tradición se afianza y consolida en las primeras comunidades cristianas que enfocan incluso los escritos del Antiguo Testamento a la luz de las ideas evangélicas.

Nótese también que la tradición cristiana, a partir de la época apostólica, se ramifica en lo que los autores han dado en llamar modalidades. Es decir, que cada escritor, testigo y eco de la tradición, se detiene con preferencia en algún aspecto fragmentario, de modo que, aunque coincidan en la misma fe y sean guiados por el mismo espíritu, no son sino riachuelos o derivaciones de otra corriente más caudalosa que, para ser conocido y valorada, necesita ser recogida y organizada para formar un todo, mediante la suma de las tradiciones parciales ${ }^{11}$.

11. Sobre las relaciones entre Escritura y Tradición hay en nuestros dias abundante literatura. Pruedle vemsle P. Asvex, "Ecriture et Tradition. A propos de livres récents": Ephemeridels theologiaxe lovaniehses 41 (1965) 491529. Es un buen artículo informativo y razonado solbre las relaciones enitre Esicnitura y Tradición en el que se examinan las posturais de los tó́logos modiernois que se comentan y que, como concluye el propio Asveld, provienen más de vertiente teológica que de la exegrética y esscrituraria. Así y todo resultia interesantísimo, pulesto que da una visión de conjunto sobre lols temas mási candentes que constituyen los puntos die discusión entre católicoss y protestantes, como así mismo los diversos maticels dentro del catolicismo en torno a la interpretación die la doctrina del C. Tridentino y a las mismals relaciones entre Esicritura y Tradición. Lois autores comentadois son: Y. M. J. CoNGar, La tradition et les traditioms. II E'sisiai théalogique, París 1963; J: R. GeiselmanN, Düe Heillige Schrift und die Tradition. Qualestiones disputataie, Fribourg-Baile-Vienne 1962; ID. Schrift und Tradition. Mariologisiche Studiven, herausgegeben voin der deutsahen Arbeitsgemeinschafft für Mariologie, Essen 1962; J. BEUMER, Die mündliche Utbertieferung als Glaubensiquelle. Handbuch der Dogmengeschichtie, herausgegeben von M. SchmaUs und A. GrILlmeier, IV, Fribourg-Bale-Vienne 1962.

Seguirá, sin duida, ahonidanido la invesstigación teológica en estos problemas, perro, al menos entre los católicos, esstá ya resuelta la icuestión de fondo sobre las relacioness entre la Eiscritura y la Tradición, puesto que el Concilio Vaticano II ha exaltardo la ligación íntima entre ambas con expressiones de rico contenido dogmático que a la vez que iluminan y orientan, sintetizan la auténticia docitrina de la Iglessia.

En la Clonstitución Dogmática DEr Verbum, sobre la divina revelación, se hablia concisa, plero profunda y claramenite, de este tema. Todo el cappítulo II, sobre la transmisión de la revelación divina, está consagrrado, como lo indica el título, a la Eiscritura y la Traldición. Sobre las relacioness entre ellas, no puedie ser más claro y terminante el pensiamiento conciliar. Nos limitamos a entrestaclar algunais frasles aue no necesitan comentariois:

"Eista sagtraidla tradición y esta Esicritura sagrrada de uno y otro Testamento son como un espeljo en que la Iglesiar... contiemipla" etc. (n. ${ }^{\circ} 7$ ).

"Assí, pues, la sagradia Tradición y la Sagradia Esicritura están estrechamente trabadas y comuniciadas lentre sí. $Y$ es aisí que amibas, por manar del mismo manantial divino, confluyen en crierto modo en uno y tienden al mismo fin. Efectivamente, la Sagradla Escritura es hablia die Dios, en cuanto que, por inspiración del Espíritu idivino, ise conisigna por escrito; y la slagirada tradición transmínite íntegrramente a los' sucesorres de loss apióstoles la plalabra de Dios..." (n.0 9). 
Por añadidura, y seguimos recogiendo las atinadas consideraciones de los críticos más solventes, la tradición como tal no es precisamente un cuerpo doctrinal estático, sino dinámico, de tal forma que el progreso de los tiempos, las necesidades de la Iglesia, el contacto con ambientes nuevos, la aparición de las herejías, el choque entre la mentalidad hebrea, la irrupción del paganismo en la iglesia naciente, etc., provocan lógicamente frecuentes intervenciones de los Apóstoles que marcan las directrices a seguir, o recuerdan las doctrinas inconmovibles, en conformidad con el testimonio paralelo de los escritos evangélicos y de la Tradición.

Iglesia y Palabra de Dios.

La Iglesia ha de incorporar a su existencia y vivificar íntegramente la Palabra de Dios. ¿Cómo llegará a conseguirlo? Esto equivale a formular un problema antiguo y nuevo que ha dado margen a una problemática interesante y a una proliferación extraordinaria de libros y de artículos, enredados en complicada controversia ${ }^{12}$ sin que se haya descubierto el punto de coincidencia entre las diversas tendencias. De una parte la teología protestante ha girado mucho tiempo sobre el eje constante de la "sola Escritura", mientras que la teología católica ha estimado que es inseparable e indestructible el binomio: Escritura-Tradicición. Con referencia al pensamiento protestante actual es evidente que se dibujan dos tendencias, la tradicional intransigente y otra más moderada que no desdeña totalmente el valor de la tradición eclesiástica ${ }^{13}$. Como prueba de la flexión teológica de una parte del protestantismo

\footnotetext{
"La sagrada Tradición y la Sagradia Escritura constituyen un sólo depósito s.g graido de la palabra de Dios encomendarda a la Iglelsial.." (n.0 10).

"Es, pues, evidente, aue la sagrada Tradición, la Sagradla Escritura y el magisterio de la Iglesia, por designio sarientísimo de Dios, se traban y asocian de forma que uno no subisiste sin lois otrois..." (n.o 10). (Concilio Vaticano II. Constituciones. Decretos-Dieclaracionest. Edic. B. A. C., Madrid 1966.)

12 Y. M. J. CoNGAR. La Traidhilion et leis traiditions. I Essai historique París 1963; A. MrCHel, "Tradition": D. T. C. XV, 1.252-1.350; P. Lengsfeld, Ectrithure et Ég'hise dams le dialogue aiecuménique, París 1964.

13 G. EBEisING, Die Religion in Geschich hite und Gegenwawt, VI, 976-984; O. Cultumanis, La trmdition, Neúchätel-París 1961; A. C. Outuer, The Chrisitian Tradition and the Unity we Serek, New York 1957; A. BENOIT, L'actuallité des Peres de l'Eglise, Neúchätel-París 1961; F. LeEnHardr, "Sola Scriptura" ou Ecriture et Tradition"?: Etudes theologriques et religieuses (1961) 5-46.
} 
cabe citar la Cuarta Conferencia mundial sobre "Fe y Constitución" celebrada en Montréal en $1963^{14}$.

Los teólogos católicos coincidentes en admitir la existencia de las dos fuentes de la revelación, en consonancia con la definición dogmática tridentina, tampoco han llegado a un acuerdo sobre las relaciones entre la Escritura y la Tradición, como lo hemos visto más arriba. El cotejo entre el Decreto del Concilio de Trento y la redacción del proyecto en el que se afirmaba que la verdad revelada estaba contenida "en parte" en los libros inspirados y "en parte" en las tradiciones no escritas ${ }^{15}$ suscitó interpretaciones encontradas y polémicas sobre las relaciones entre la Escritura y la Tradición ${ }^{16}$ que se manifestaron incluso en la primera sesión del Concilio Vaticano II. También algunos teólogos católicos contemporáneos hablan de la suficiencia de la Escritura sola ${ }^{17}$, aunque en diverso sentido que los protestantes, pero, en general, se propende a considerar la Escritura y la Tradición, mucho más íntimamente relacionadas de lo que se pensó en el pasado, viniendo a ser como una sola fuente de la fe y de la Teología ${ }^{18}$.

\section{A) Primeros balbuceos en torno a la inspiración sociológica.}

Todas las empresas humanas pasan por etapas de gestación y desarrollo, antes de lograr su plenitud. El esfuerzo de los teólogos y bíblicos ha sido ingente, sobre todo a partir del siglo xIx, en lo tocante a estudiar la naturaleza y la psicología de la inspiración. También los docu-

14 J. L. Leuba, Tradition et traditions. (Trabajos de la comisión preparatoria del Congr'eso); J. P. GABUS; Comment replenser dams une pebrispelative protestante le rappport Ecritume-Tradition, Istina 1963.

15 No citamos bibliograffía porque tocamos estie tema tan sólo die refilón, pero baste con recordar los nomibres de varios autores renombrados: Tavard, Congar, Geiselmann, Lennerz, Schauf, etc.

16 J. DUPONT, "Écriture et Tradition": Nouvelle revue théologique 85 (1963) 449-458; A. TRAPE, "De Traditionis relatione ald S. Scripturam iuxta concilinum Tridentinum": Augustinianum 2 (1963) 253-289; A. M. DUBARLE, "Quaelques notes" sur Ecriture et Traidition": Revue des sciencies philosonhiques ot religrieuses (1964) 274-280.

17 Y. M. J. CONGAR, La triadition elt les traditions, I Eisisai hristorique, 139-150; A. LANG, Sacmae Scripturno suffichentrix? De Siripturia et Traditione;

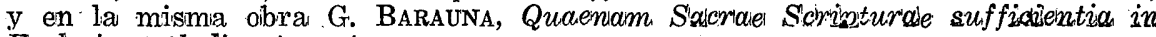
Ecclesia clatholica temeatur.

18 Noss remitimos a la nota 11 de nuesstro trabajo. Vid. L. Alonso Schökbí, La pailabra inspirada (La Biblia a la luz dle la ciencia del lenguaje), Barcelona 1966. 
mentos pontificios contribuyeron sobre manera a encauzar las discusiones y a dar con venturosos hallazgos. Unos y otros habían dado pinceladas significativas que actualizaban y exaltaban la contribución humana, sin olvidar la divina, en la redacción de los libros santos, aunque faltaba por señalar, al menos de modo explícito, el carácter social de la inspiración. Decimos que de modo explícito, porque hemos podido ver en las páginas precedentes que existía un señalado anhelo por relacionar más íntimamente los libros sagrados con el pueblo de Dios, con la comunidad de la salvación. Como el manoseado apotegma moral repite que "sacramenta propter homines", también había que proclamar que la Escritura es para la Iglesia, para los hombres.

Recordábase a este propósito que no se debe considerar al hagiógrafo, al hombre inspirado, como un ser aislado ${ }^{19}$, un receptor del pensamiento divino desconectado de la comunidad de salvación, como si sobre él se posara el carisma divino, sin ulteriores perspectivas, siendo así que es miembro de una colectividad viva y concreta. Pensaban incluso atinadamente que, aplicando la teología de los carismas, gracias gratis datas, las comunicaciones inspiratorias habían de afectar no sólo a la persona, sino también a la comunidad.

En 1950 Dom C. Charlier ${ }^{20}$ desbrozaba el camino, sospechando que la inspiración escrituraria debía tener tales y tan amplias dimensiones que llegara hasta la vida del medio ambiente. Aunque sus ideas no hallaran aún formas expresivas adecuadas, es indiscutible que se trata de un atisbo estimable que merece nuestro reconocimiento. Pero aún dice más, puesto que al referirse al autor, afirma que se reconoce como inspirado al libro, porque su autor es un inspirado, pero que este reconocimiento arranca del hecho de que el hombre inspirado ejerce una función social en la comunidad en virtud de un mandato divino.

Aunque las expresiones no sean del todo felices, se abre con ellas una nueva perspectiva sobre las dimensiones sociales de la inspiración bíblica, brindando un interesante tema de estudio a los especialistas.

19 A. BARUCK - H. CAzelles, Introducción a la Büblia I, Barcielona 1965, 56-57: “El inspipirado en la comunidaid".

20 C. CHARLier, La lecture chreltienne de la Bible, Mareidsous 1950,119. 
B) Las relaciones entre la Escritura y la Iglesia, base de la teoría DE K. RAHNER.

El P. Rahner, profesor de Teología Dogmática en la Facultad de Teología de Insbruck, es en la actualidad una de las personalidades más destacadas y brillantes del pensamiento católico, tanto por su vasta y original producción teológica, como por la singularidad de sus ideas y por el prestigio que se ha ganado en buena lid, gracias a sus afortunadas excursiones por la problemática teológica contemporánea, llegando a ser uno de los exponentes más calificados y representativos del pensamiento católico de nuestro tiempo. Con ser esto cierto, es posible que la nata más característica de su obra literaria y teológica haya que buscarla en su peculiar instinto para formular los problemas más acuciantes y derramar sobre ellos el tipismo de sus ideas y su peculiar manera de dar nuevas formas al pensamiento, rompiendo los viejos moldes de la escolástica tradicional y abriendo cauces a una sana renovación de la teología en sus métodos expositivos, en la línea preferida por los teólogos actuales.

Duélense algunos comentaristas de que no siempre sean afortunadas las incursiones de los teólogos en los dominios de la Sagrada Escritura, cual si se tratara de un predio reservado a los bíblicos. En nuestro caso es evidente que el tratado escriturístico de la Inspiración es esencialmente teológico $\mathrm{y}$, por tanto, ampliamente apto para la especulación teológica.

La fama bien difundida y cimentada del P. Rahner, con el respaldo de sus numerosas y sólidas publicaciones, ha cobrado nuevo brillo, gracias a su participación como perito en el Concilio Vaticano II.

No siempre han sido acogidas sus ideas con general aplauso, ya que se trata de desbrozar campos complejos o no bien explorados y no resulta tarea fácil fundir todas las opiniones en materias oscuras y discutibles. Con respecto al tema que nos ocupa, acaso sea verdad que a veces sus ideas son sutiles, que sus fórmulas expresivas y sus piruetas intelectuales exigen un gran esfuerzo mental para captar íntegramente su pensamiento. No olvidemos, por otra parte, que es un escritor alemán que expone a su modo y que sin duda resultará más asequible a sus connacionales, mientras que resulta menos transparente para otras men-" talidades, por ejemplo, la latina. 
Tras estas observaciones que pudiéramos llamar ambientales, digamos que el P. Rahner expuso por vez primera su original punto de vista sobre la inspiración en una conferencia pronunciada en la Universidad de Würzburg en 1956. Más tarde ampliaría los puntos fundamentales de su teoría hasta formar un folleto de 88 páginas que apareció en $1958^{21}$.

La exposición del P. Rahner se inicia con la enumeración de ciertos temas relacionados con la inspiración que, a su juicio, no han sido resueltos satisfactoriamente por la teología tradicional. Entre ellos enumera como fundamentales los siguientes:

1. ¿Cómo ha de entenderse que Dios es autor literario de la Biblia?

2. ¿ ¿Cómo entender la revelación apostólica que muchos estiman necesaria, como criterio de inspiración?

3. ¿Es cierto que el hagiógrafo sea inspirado sin tener conciencia de ello?

4. ${ }^{\circ}$ Modo de compaginar la infalibilidad de la Escritura y la del magisterio eclesiástico, salvando la ilusión de hallarnos ante fuentes yuxtapuestas, de modo que la Tradición se añada a la Escritura.

Formulada así la problemática sobre estos puntos por su misma naturaleza complicados y difíciles, pasa a exponer, en su segunda parte, los principios generales que constituyen la base de su original teoría y que, a su modo de ver, irradian luz y soluciones para aclarar las dificultades expuestas en los preámbulos, lo que constituye la tercera y última parte.

No es nuestro intento analizar y discutir cada uno de los puntos mencionados, cosa que ya llevaron a cabo especialistas de toda solvencia ${ }^{22}$, sino tan sólo sintetizar las ideas básicas que sirvan a nuestro propósito de subrayar el carácter social de la inspiración.

Dios, afirma Rahner, quiso con voluntad absoluta fundar la Iglesia y desplegó en la fundación de la Iglesia primitiva (Urkirche) ciertos

21 K. RAHNER, Über die Schriftinspiration. Eista primera redacción fue revisada y ampliada en Ubbr die Schriftinspiraltion, Freiburg 1958.

22 P. BENOIT, "Révélation et Inspiration selon la Bible chez Saint Thomas et dans les discussions modigrnels": Rervue biblique 701 (1963) 321-370; A. IBÁÑEZ Arana, "La teoría de Rahner sobre la Inspiración": Lumen 9 (1960) 193-209; 11 (1962) 193-213; L. ARNALDICH, "El concepto de insipiración bíbilica y una hipótesis del P. C. Rahner": Verdad y vida 17 (1959) 99-112; P. GRELot, La Bible Parole de Dien, Tournai 1965, 42. 
desvelos que no habían de ser ya necesarios en su desarrollo posterior. Entre los elementos esenciales constitutivos de la Iglesia ocupa un puesto primordial la Escritura. La del Antiguo Testamento como parte de la prehistoria de la Iglesia que, por su relación con ésta, había de conservar su vigencia; la del Nuevo Testamento como la expresión de la fe y de la vida de la Iglesia que sería norma universal para todos los tiempos. Dios, con voluntad absoluta, quiere y funda la Iglesia primitiva y los elementos constitutivos de la misma, entre los que se halla la Sagrada Escritura. De este modo, Dios quiere y crea la Sagrada Escritura, siendo, por tanto, su autor y su causa inspiradora; ha escrito los libros en que se contiene la fe de la comunidad de salvación por El mismo fundada por un "acto de orden histórico y escatológico que se inserta en el porvenir humano". En definitiva, es Dios autor de la Escritura, por lo mismo que es autor de la Iglesia ${ }^{23}$, puesto que aquélla es elemento constitutivo y esencial de ésta en su fase primordial.

De este modo se coloca la inspiración en la línea general de toda la obra salvífica del Espíritu Santo. En tal supuesto, el Nuevo Testamento refleja la fe de la Iglesia apostólica, sus autores tienen conciencia de llevar a cabo una función al servicio de la Iglesia, la Iglesia postapostólica ve en la Escritura su regla de fe, connatural con la misma Iglesia y es como entra en la misma línea el magisterio que guía la Iglesia.

Rahner acepta la definición del Concilio Vaticano I ${ }^{24}$ y en general la doctrina de las Encíclicas pontificias sobre la inspiración y, en consecuencia, sostiene que Dios es autor literario de la Biblia, lo que equivale a dar como necesario y real un influjo divino en el entendimiento y en la voluntad del hagiógrafo, como también en sus facultades ejecutivas. Sin embargo, atenúa en cierto sentido dicho influjo: Dios concibe, quiere y ejecuta el libro en virtud de una predefinición formal: mediante ella influye en el entendimiento del hagiógrafo que conoce lo que El quiere y como $\mathrm{El}$ quiere y también por ella llega a la voluntad que viene condicionada no directamente, sino por las causas segundas, es decir, las circunstancias extrínsecas que movieron al autor humano a escribir.

23 Coinciden con esta idea P. LENGSFELD, Tradition, Écriture, et Égilise, 213: "Il se révelie ausssi comme l'auteur" de ces feritures, exactement comme jil est l'auteur de l'Église" y J. ScHILDENBERGER, Questions théologiques aujourd"hu? y algunos otros citados por P. GRELOT, o. cl., 42.

24 Ench. B., 79. 
Reconoce que no es necesaria la inspiración en el momento de redactar el libro. El sujeto de la inspiración es la Iglesia que recibe el libro por ser la expresión auténtica de sus ideas, de su fe y de su vida, haciéndolo suyo.

No se puede negar que la hipótesis del $P$. Rahner es original y nueva. Como tal marca el rumbo de una inquietud científica despertadora de investigaciones que pone sobre el tapete una cuestión interesante en torno a los problemas y misterios de la divina inspiración. Por eso y porque es hermosa la idea de englobar a la Iglesia y no sólo a Dios y al hagiógrafo, en la producción de la obra literaria, las elucubraciones de Rahner han sido acogidas con simpatía y benevolencia, como una aportación valiosa a la renovación y al progreso de la investigación bíblica. Por eso nos parece ecuánime y certero el juicio general de A. Ibáñez Arana ${ }^{25}$ : "La idea central, siempre que no se la quiera hacer pasar por explicación suficiente de la inspiración, parece estar llamada a enriquecer nuestra vieja teología, en la que no caben ni grandes revelaciones, ni catastróficas revoluciones! pero que está siempre abierta a un saludable desarrollo, por las síntesis de lo viejo y de lo nuevo".

Esta hipótesis, opina P. Grelot, extiende considerablemente el horizonte de la teología clásica.

Así y todo, se le han opuesto defectos y dificultades, como si ofreciera puntos flacos, o no comprobados, desde luego que al margen de la ortodoxia.

Se ha estimado que no se salva en esta teoría el sentido y la naturaleza del influjo carismático exigido por los documentos pontificios que lo describen como inmediato y concreto.

$\mathrm{Ni}$ han faltado quienes han querido ver cierta afinidad ideológica entre la postura del P. Rahner y la doctrina de la aprobación subsecuente ${ }^{26}$ reprobada por el Cóncilio Vaticano I ${ }^{27}$, pero, en realidad, nada hay de común entre ambas, como no sean lás apariencias, puesto que el acto aprobatorio de la Iglesia, según el P. Rahner, es inspirado por Dios y no un acto de la Iglesia sola.

\footnotetext{
25 A. IBÁÑEZ Arana, "Obsservaciones a la teoría de K. Rahner, sobre la inspiración": Lumen 11 (1962) 213.

26 D. HANEBERG que diefendió que podía estimarse como inspirado un libro que fuera aprobado pior la Iglesia, se retractó después' del Concilio Vaticano I.
} 
Quizás la dificultad más consistente y transcendental haya que enmarcarla en su ineficacia universal frente a los diversos casos que pueden presentarse ; en concreto, no parece que pueda aplicarse por igual al Antiguo y al Nuevo Testamento. Se reconoce sin esfuerzo que la aplicación pudiera ser válida y fructuosa respecto del Nuevo Testamento, pero no ocurre lo mismo con relación al Antiguo. Parece lógico que si Ia hipótesis es válida debe aplicarse en la misma línea a todos los libros que foman la Sagrada Escritura.

Como ya observaran no pocos críticos, incluso el mismo P. Benoit ${ }^{28}$, que también se hace eco de esta dificultad, la teoría del P. Rahner pierde vigor y seguridad cuando se enfrenta con el Antiguo Testamento. Si la Escritura es, en efecto, elemento constitutivo de la Iglesia, es evidente que éste se verifica y resulta más claro para la Palabra apostólica que constituye la regla de fe de la misma Iglesia. Dicha Palabra apostólica, segura y auténtica, sirve de base a la autoridad de la Iglesia y desempeña un papel esencial e insustituíble ${ }^{29}$. Lo que no quiere decir que la Palabra apostólica escrita absorba en exclusiva todo el caudal de la doctrina revelada, puesto que la tradición conserva igualmente su vigencia.

Parece evidente que esta regla de fe que se deriva del testimonio conjunto de la Escritura y de la Tradición, no puede aplicarse en la misma medida al Antiguo Testamento, por lo que no resuelve, sino que deja en pie, el problema total de la inspiración escrituraria ${ }^{30}$.

28 P. BENoIT, "Introduction à la Bible et Ouvrages geéneraux": Revue biblique 67 (1960) 278: "No puede explicar la inspiración del Antiguo Teistamento sin evidente embarazo".

29 M. J. CoNGAR, "Insppiration et apostollicité de l'Église": Revue dies scien ces philosophiques et religièuses, Le Saulchoir (1961) 32-42.

30 A. IBÁÑEZ ARANA, "La tieoría de Rahner sobre la inspiración": Lumen 9 (1960) sintetiza así la idea del P. RAHNER: "el Antiguo Tesitamento pertenece a la fundación de la Iglesia como la parte die su historia que debía de piermanecer. En su segrundo artículo, Lumen 11 (1962) 208-209, de forma objetiva y razonada esgrime las dificultaides que pressenta la teoría del P. Rahner aplicaida al Antiguo Testamento. M. Alvarez GóMEz, "La inspiración bíblica según Rahner": Stud. Leg. 3 (1262) 115-169; A. M. ARTOLA, "Juicios críticos en torno a la "Inspiración bíblica" del P. Rahner": Lumen 13 (1964) 384-408. Terminada ya nuestra exposición recibimos la Introducción Gerneral a la Sagradia Escrittura, por varios autores españoles y en el ella G. PÉREz RoDRíGuEz, a quien pertenece el Tratado de Inspiración, sintetiza bien la doctrina ide Rahner y coincidie con nuestras apreciaciones en las pp. 60-63. J. J. BRown, "Inspiration in the Bible according to K. Rahner. A Critical Analysis": Alma Studies 7 (1963) 19-37. 
C) Las analogías de la inspiración, fundamen'to de la teoría de P. Benoit.

P. Benoit, lo saben todos los iniciados en los estudios bíblicos, goza de acrisolado prestigio en todas las esferas eclesiásticas y más particularmente en los ambientes consagrados a los estudios escriturarios. Su firma es máxima garantía de seriedad y solvencia. Maravilla la ductibilidad de su inteligencia y de su pluma, abarcando una increíble diversidad de temas, sin que por ello desmerezca su aire de autor compacto y documentadísimo, tanto en las obras de investigación teológica y bíblica, como incluso en el enjuiciamiento de las obras que analiza en su constante actividad literaria, sobre todo, como colaborador asiduo de la Revue Biblique.

Pues bien, P. Benoit expuso sus peculiares ideas sobre la inspiración bíblica en un Congreso bíblico de Lovaina y su conferencia apareció impresa, con otros trabajos de dicho Congreso, en Sacra Pagina, ParísGembloux, 1959, T. I, pp. 86-99, con el título "Les analogies de l'inspiration".

Su exposición es mucho menos conceptuosa y complicada que la del P. Rahner, por lo que resulta más diáfano y asequible su pensamiento, sin que ello prejuzgue los méritos de su obra.

El Espíritu Santo obra en el pueblo de Dios a través de muchas clases de carismas que pueden agruparse bajo el título común y genérico de inspiraciones. Tales carismas hay que considerarlos en relación con los diversos oficios que han desempeñado los hombres en el transcurso de la historia de la salvación. He aquí las diversas categorías: unos fueron destinados a obrar y con sus obras actuaron como mensajeros de Dios; otros, a hablar en su condición de profetas o de apóstoles; otros a escribir, para fijar la Palabra de Dios y hacerla asequible a las futuras generaciones. P. Benoit cree que son correlativos los tres modos citados. Estas clases de inspiración, típicas en la transmisión de la Palabra de Dios en las épocas históricas en que la revelación estaba en vías de desarrrollo, se ha prolongado a través de los tiempos y tiene actualidad y vigencia en nuestros días: en forma de asistencia del Espíritu Santo a la Iglesia, calificada ya como inspiración por algunos teólogos antiguos.

Descartados los primeros modos de inspiración que no nos interesa ahora, dado el objetivo directo y concreto de nuestra exposición, parece 
que es razonable el enfoque de P. Benoit con referencia a la inspiración para escribir. La idea, además de ser fecunda, no parece desprovista de fundamento. Acaso el sistema no haya logrado una armazón orgánica, pero ofrece ideas aprovechables que poco a poco van siendo tenidas en cuenta y ampliadas por teólogos y biblistas de nota. Así, por ejemplo, P. Grelot ${ }^{31}$, que hace salvedades respecto de los otros dos restantes modos, pero que la encuentra correcta en lo tocante al escribir. En las páginas siguientes amplía dicho autor y apoya la tesis de $\mathrm{P}$. Benoit pasando revista a los carismas relativos a la Palabra de Dios.

En el Antiguo Testamento, en virtud de una acción divina, la Palabra de Dios fue predicada, conservada y explicada. En efecto, fue confiada, de diversos modos, a los profetas que constituyeron categoría a parte. Pero también otros se beneficiaron de carismas inspirados en el desempeño de sus específicas funciones, como los ancianos, los sacerdotes, los cantores e incluso los escribas del tiempo posterior a la cautividad que colocaron su sabiduría al servicio de la Palabra de Dios y de la tradición fundada en la Escritura. En resumen, es posible que todos estos portadores de la Palabra divina se beneficiaran de un carisma inspirativo.

En el Nuevo Testamento todo aparece más claro, puesto que los oficios eclesiales destacan con mayor precisión y firmeza, de tal modo que ha podido hablarse de una teología de los carismas ${ }^{32}$, basada sobre todo en las epístolas paulinas ${ }^{33}$.

Cabe señalar, ante todo, que el carisma apostólico forma categoría a parte, no sólo porque ocupa siempre el primer lugar en los catálogos paulinos, en los que se pasa lista a los carismas, sino y sobre todo, porque es punto central y sustancial de la revelación en la época apostólica ${ }^{34}$. Esta revelación se desarrolla bajo la acción del Espíritu Santo.

Por otra parte, parece lógico establecer un paralelismo entre los profetas del Antiguo Testamento y los apóstoles del Nuevo, pero así como en el Antiguo hubo otras personas partícipes de los divinos caris-

31 O. c., 44.

32 I Corr. 12, 28: ssegún la dispposición de Dios en la Iglesia, primero apóstoles, luego profetas, luego dioctoress, luego el podier die los milagros, las virtudes; desppués las gracias de cunación, de asistencia, de gobierno, las gténeross die lenguas...

33 Hay muchas obras fundamentales y orientadoras sobre el tema, pero, podiemos señalar algunas, como E. B. Alro, Premieme ézitre aux Coxinthiens, París 1935, 317-339; F. Prat, Théologie de Saint Paul, I, París 1938, 398-502.

34 Puede hallarse abundante material informativo, así como bibliográfía copiosa y sellectia en J. CoLson, Les functions eccillesjaules aux deux prémiers siecles, Brugeis-Piarís 1956, 11-71. 
mas, esto mismo pudiera decirse de los tiempos apostólicos en que parece ser que, además de los Apóstoles, hubo otros hombres beneficiarios de dichos carismas llamados por los modernos funcionales y que afectarían a ciertas personas que desempeñaron oficios de responsabilidad en las primitivas comunidades apostólicas, actuando como órganos de la tradición, sobre la que también recaería el carisma denominado funcional. Tal ocurriría con aquellos que no eran apóstoles, como Lucas y Marcos, pero que, en esta hipótesis, pudieran ser considerados como ministros encargados de desempeñar funciones carismáticas en la comunidad eclesial. Esto, es lógico, no ocurriría como una exigencia del cargo, sino por disposición providencial. También resulta interesante esta observación para explicar la inspiración de cuantos redactores ponen la mano en un libro, hasta su fijación definitiva, puesto que todos ellos disfrutarían del carisma en virtud de un designio divino.

Es decir, que habría que relacionar la inspiración bíblica con los demás carismas y no considerarla como un fenómeno único y aislado, tal como se ha hecho en la teología tradicional. El nombre genérico inspiración valdría para todos los casos en que, por voluntad de Dios, han intervenido los hombres en la transmisión o conservación de la divina revelación.

Aún se pueden alargar las consecuencias de esta teoría, puesto que la doctrina sobre los carismas funcionales alcanzarían también al magisterio eclesiástico que de oficio es depositario y guardián de la revelación.

Los críticos irán sistematizando y apoyando escriturariamente estas ideas, $\mathrm{o}$ acaso pongan en evidencia su falta de solidez. Es menester tener faciencia y objetividad, reconociendo que sus puntos de reflexión merecen ser estudiados y meditados, puesto que pueden ser útiles, aunque no se admita la teoría, para una mejor inteligencia de la naturaleza de la inspiración.

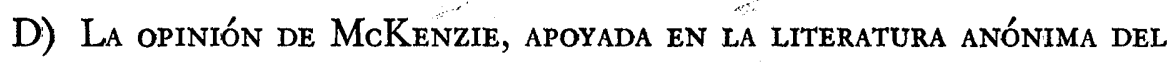
Antiguo Testamento.

Otro nuevo intento de acentuar el carácter sociológico de la inspiración, escogitado y propuesto por McKenzie ${ }^{35}$ en 1962. No tiene, en

as J. L. MCKenzIe, "The Social Character of Inspiration"; Catholic Bibli- 
verdad, el empaque y la enjundia de la exposición de P. Benoit, antes bien se muestra endeble en su construcción, tal como lo ha demostrado la crítica:

Se basa en una constatación de la crítica escrituraria que no deja de ser cierta, aunque no sea admisible la interpretación que se hace de la misma. El hecho de referencia es este: en el Nuevo Testamento cada libro se atribuye a un autor determinado que lo encabeza y es reconocido como tal, salvo casos aislados en los que se ha puesto en tela de juicio y se discute aún la paternidad de algún libro. En cuanto al Antiguo Testamento las conclusiones son bien distintas. La mayoría de sus libros son de autores ignorados, sin que ello afecte a la inspiración que no va vinculada a ningún autor concreto. El caso del Antiguo Testamento, observa nuestro autor, es muy significativo: los autores de estos libros se preocuparon bien poco, lo mismo que la tradición inmediata, por conservar los nombres de los redactores, porque tenían conciencia de desempeñar una función social en la que la persona contaba poco, es más, era la sociedad la que escribía y los autores actuaban como miembros de la misma, resultando del todo indiferente el que ejerciera esa función una u otra persona determinada. Eran, en suma, la voz de Israel.

Claro que este peculiar modo de dar relieve sociológico a la inspiración nada tiene que ver con los propugnadores de la "historia de las formas" -Dibellius, Bultmann, etc.- quienes estiman que los Evangelios sinópticos no son tanto obra de los evangelistas, como de la comunidad cristiana.

Así y todo, esta hipótesis parece ineficaz, por carecer de sólido fundamento y basarse en equívocos cuyo descubrimiento resulta fácil para los conocedores de la crítica escrituraria. Cabe admitir que en algunos casos esporádicos y restringidos del Antiguo Testamento, por ejemplo en algunos salmos, pueda adivinarse la voz de Israel que ora o habla, pero esto dista mucho de ser normal. Antes debe pensarse que suele ocurrir todo lo contrario: habla o escribe el autor humano que transmite la voz de Dios. Se trata, por tanto, de averiguar quien es el sujeto del carisma, si el autor del libro o la comunidad, o pueblo de Dios. Nadie niega que los escritores vivieran en una comunidad y participaran de sus preocupaciones, de sus vicisitudes y de su misma vida. Pero,

cal Quarterly 24 (1962) 115-124; D. J. Mc CARTHX, "Personality, Society and Inspiration": Theological Studies 24 (1963) 553-576; J. L. TOPEL, "The Social Theory of Inspiration; Rahner and Me Kenzie": Alma Studies 7 (1963) 117. 
una cosa es contar con el factor del medio ambiente que ejerce cierto influjo en el escritor y otra muy distinta sostener que la inspiración es comunitaria o colectiva. $\mathrm{P}$. Benoit señala con precisión que se trata de una inspiración "no colectiva, sino para la colectividad" ${ }^{36}$.

Se impone, por consiguiente, seguir manteniendo las ideas tradicionales que proclaman el carácter personal de la inspiración. Por varias y serias razones. Las ideas sociológicas que exaltan el valor preponderante del grupo, con mengua de la persona, distan mucho de ser convincentes. Más bien depende la comunidad de las personas que la rigen. Esto es más claro en la historia sagrada en la que es Dios quien suscita y dirige a su pueblo. Desde el punto de vista dogmático llegamos a las mismas conclusiones.

La Encíclica Providentissimus define la inspiración como un influjo característico en las facultades de los autores humanos concretos y en la misma persuasión abunda el Concilio Vaticano II :

"En la composición de los libros sagrados Dios elegió a los hombres de los que se valió dentro del uso de su fuerza y facultades, de suerte que obrando $\mathrm{El}$ en ellos y por ellos, consignaron por escrito, como verdaderos autores, todo aquello que El quisiera." ${ }^{37}$

\section{P. Dictinio Rodríguez Bravo, O. S. A.}

36 Cfr. Concilium 10 (1965) 23.

37 Const. Dogm. "Dei Verbum", BAC, Madrid, 1966, n. 11. 